\title{
Originals
}

\section{Effects of chronic, urea-induced osmotic diuresis on kidney weight and function in rats}

\author{
Y.Ogino, S. Okada, Z. Ota \\ Third Department of Internal Medicine, Okayama University Medical School, Okayama, Japan
}

Summary To study the effects of chronic osmotic diuresis which were not associated with hyperglycaemia on the rat kidney, osmotic diuresis was induced by i. v. infusion of urea. A $5 \mathrm{~mol} / \mathrm{l}$ urea solution was continuously infused at a rate of $100 \mathrm{ml} \cdot \mathrm{kg}^{-1} \cdot$ day $^{-1}$ on the basis of body weight on day 0 . Duration of infusion was $2,6,10$ or 14 days. Control rats received continuously infused Ringer's solution. Urea-treated groups developed osmotic diuresis (urine flow $=$ about $0.04 \mathrm{ml} \cdot \mathrm{min}^{-1} \cdot 100 \mathrm{~g}$ body weight ${ }^{-1}$ ) comparable to that in rats with experimental diabetes mellitus induced by i.v. streptozotocin $(55 \mathrm{mg} / \mathrm{kg})$, however urea-induced osmotic diuresis was not associated with blood glucose level increases. Compared with their controls, rats receiving urea for 2-14 days had markedly increased kidney weight. Rats receiving urea for 10 days showed greatest kidney weight increase, $0.565 \pm 0.044 \mathrm{~g} / 100 \mathrm{~g}$ body weight (mean $\pm \mathrm{SD}$ ), representing a $53 \%$ increase compared with the control $(0.369 \pm 0.034 \mathrm{~g} / 100 \mathrm{~g}$ body weight). Kidney weight was associated with increases in kidney protein content. In contrast, none of control kidney weight values differed significantly from day 0 values (=normal rats; $0.387 \pm 0.028 \mathrm{~g} / 100 \mathrm{~g}$ body weight). Creatinine clearance values in urea-treated groups were also higher than those in controls. The maximum value, $0.65 \pm 0.17 \mathrm{ml} \cdot \mathrm{min}^{-1} \cdot 100 \mathrm{~g}$ body weight $^{-1}$, was recorded in the 14-day group and was significantly higher than the corresponding control value $\left(0.34 \pm 0.07 \mathrm{ml} \cdot \mathrm{min}^{-1} \cdot 100 \mathrm{~g}\right.$ body weight $\left.{ }^{-1}\right)$ $(p<0.001)$. Urea clearance values were also significantly higher in urea-treated groups than in respective controls. This study suggests that osmotic diuresis may induce renal hypertrophy/hyperplasia and glomerular hyperfiltration immediately after development of diabetes. [Diabetologia (1994) 37:225-231]

Key words Osmotic diuresis, urea, renal hypertrophy, glomerular hyperfiltration, diabetes, rat.
Renal hypertrophy and glomerular hyperfiltration develop early in the course of diabetic nephropathy [1-3]. Mogensen et al. [4] delineated five stages of diabetic nephropathy in insulin-dependent diabetes mellitus and defined the first phase as the appearance of renal hypertrophy and glomerular hyperfiltration. Studies

Received: 3 June 1993

and in revised form: 6 September 1993

Corresponding author: Dr. Y.Ogino, Third Department of Internal Medicine, Okayama University Medical School, 2-5-1 Shikata-cho, Okayama 700, Japan

Abbreviations: DM, Diabetes mellitus; ID, inner diameter; OD, outer diameter. have confirmed that similar phenomena appear in animal models [5]. Renal hypertrophy and glomerular hyperfiltration are also considered bases of the progression of diabetic nephropathy to the next phase [6]. It is noteworthy that these phenomena appear within a short period of 1.5-4 days after the development of hyperglycaemia $[5,7,8]$. However, it still is not certain whether these conditions are caused by the effects of the glucose itself, other events secondary to hyperglycaemia, or unrelated factors. It is also unknown whether renal hypertrophy precedes [9] or follows [10] glomerular hyperfiltration, and whether the causes of these phenomena are identical.

High blood glucose levels and osmotic diuresis due to hyperglycaemia are the undisputed findings observed immediately after the development of diabetes. 
What is not known, however, is whether the osmotic diuresis has negative effects on the kidney, or whether those effects are due to the hyperglycaemia itself. By inducing osmotic diuresis independent of hyperglycaemia, the effects of osmotic diuresis itself may be observed.

The present study induced continuous osmotic diuresis which was not associated with hyperglycaemia. By observing its effects on the kidney, we hoped to determine how osmotic diuresis is related to the renal hypertrophy and glomerular hyperfiltration that occurs in early diabetes.

\section{Materials and methods}

\section{Animals}

Normal male Wistar rats (Charles River Japan, Inc., Kanagawa, Japan), weighing from 235 to $305 \mathrm{~g}$ were used. Rats were housed individually in metabolic cages and received standard rat chow (Clea Japan Inc., Tokyo, Japan) and tap water ad libitum.

\section{Protocol}

The rats were assigned to three groups. One group received a continuous i.v. infusion of $5 \mathrm{~mol} / \mathrm{l}$ urea solution (Urea group); the second group received an i.v. injection of streptozotocin to induce diabetes (DM group), and the controls received a continuous i.v. infusion of Ringer's solution. A group consisting of normal rats $(n=7)$ served as a day 0 group for each of the three treatments.

In the urea and control groups, a modified version of the method described by Steiger et al. [11] was used for continuous i. v. infusion. Briefly, each rat was placed supine on an operating board and restrained under diethyl ether anaesthesia. Using sterile apparatus and aseptic technique, a longitudinal incision was made over the right supraclavicular region. The right jugular vein was exposed and ligated with $5-0$ silk at $0.5-1.0 \mathrm{~cm}$ distal to the right clavicle. The vein was bound with another suture above the clavicle and was not ligated until a catheter was inserted through the phlebotomy between the two sutures. The catheter was composed of a $43-\mathrm{cm}$ long polyethylene tube $(0.72 \mathrm{~mm} \mathrm{ID}$, $1.12 \mathrm{~mm}$ OD, No.15; Igarashi Ika Kogyo Co., Ltd., Tokyo, Japan) connected with a 4-cm long polyethylene tube $(0.28 \mathrm{~mm}$ ID, $0.61 \mathrm{~mm}$ OD, Intramedic polyethylene tubing; Becton Dickinson and Co., Franklin Lakes, NJ, USA) and with a $2.5-\mathrm{cm}$ long silicone rubber tube $(0.30 \mathrm{~mm}$ ID, $0.64 \mathrm{~mm}$ OD, Silastic medical grade tubing; Dow Corning Corporation, Midland, Mich., USA). The catheter was positioned in the vein so that the tip of the silicone rubber tube reached either the superior vena cava or the right atrium. The base of the catheter was passed subcutaneously using a metal stylet and emerged out of the midscapular region. The basal side of the catheter was passed through a specially composed metal harness and a stainless steel spring stock welded to the harness, and connected at the lower part with a sterile swivel infusion apparatus (Model 375 series; Instech Laboratories, Philadelphia, Pa., USA). The swivel was suspended just above each metabolic cage and connected at the upper part with silicone rubber tubing $(1.3 \mathrm{~mm} \mathrm{ID}, 3.33 \mathrm{~mm} \mathrm{OD}$, Model 2030-969; LKB-Produkter AB, Bromma, Sweden) to a continuous infusion pump (Model 2232 LKB Microperpex $S$ peristaltic pump; Pharmacia LKB Biotechnology, Uppsala,
Sweden) connected to a sterile bottle for the transfusion solution. The harness was sutured with $2-0$ silk to the back of each rat at four points. After these procedures, each rat was able to move without any restraint within the metabolic cage.

The solutions infused were a $5 \mathrm{~mol} / 1$ urea solution (composed of $300.3 \mathrm{~g} / \mathrm{l}$ of urea, $1.46 \mathrm{~g} / \mathrm{l}$ of NaCl, $1.12 \mathrm{~g} / \mathrm{l}$ of $\mathrm{KCl}, 1.68 \mathrm{~g} / 1$ of sodium lactate, and $20.25 \mathrm{~g} / \mathrm{l}$ of glucose) and the Ringer's solution (composed of $1.46 \mathrm{~g} / \mathrm{l}$ of NaCl, $1.12 \mathrm{~g} / \mathrm{l}$ of $\mathrm{KCl}, 1.68 \mathrm{~g} / \mathrm{l}$ of sodium lactate, and $20.25 \mathrm{~g} / \mathrm{l}$ of glucose). These solutions were deaerated and injected into the transfusion bottle through a filter (pore size: $0.45 \mu \mathrm{m}$; Millipore Corporation, Bedford, Mass., USA).

The infusion pump was calibrated using a $0.1 \mathrm{ml}$ volumetric pipette so that the infusion rate was $100 \mathrm{ml} \cdot \mathrm{kg}$ body weight ${ }^{-1}$ $.24 \mathrm{~h}^{-1}$ on the basis of body weight of each rat at day 0 . Each rat received continuous i.v. infusion from the calibrated pump.

The duration of infusion was $2,6,10$ or 14 days. The groups were termed the Urea/2-day group $(n=7)$; Urea/6-day group $(n=7)$; Urea/10-day group $(n=7)$; Urea/14-day group $(n=6)$; Ringer/2-day group $(n=7)$; Ringer/6-day group $(n=9)$; Ringer/10-day group ( $n=9)$; and Ringer/14-day group $(n=8)$.

Each rat assigned to the DM group was rendered diabetic by a single i.v. dose of $55 \mathrm{mg} / \mathrm{kg}$ of streptozotocin (Sigma Chemical Co., St. Louis, Mo., USA) dissolved in $0.1 \mathrm{~mol} / 1$ citrate buffer (pH 3.8) and injected into the tail vein. The rats were classified into the DM/2-day group $(n=6) ; \mathrm{DM} / 6$-day group $(n=8)$; DM/10-day group $(n=6)$; and DM/14-day group $(n=9)$, with time periods referring to the number of days, at the completion of the experiment, since the initial i.v. injection of streptozotocin. Rats with a negative glucose urine test $24 \mathrm{~h}$ post-streptozotocin injection and those with a blood glucose level of no more than $17 \mathrm{mmol} / \mathrm{l}$ at the completion of the experiment were excluded from the analysis.

A 24-h urine sample was collected beginning 24-h prior to the scheduled time of completion of the experiment. Each rat from the continuous infusion groups underwent laparotomy under pentobarbital anaesthesia ( $40 \mathrm{mg} / \mathrm{kg}$, i.p.), and a blood sample was taken at the bifurcation of the abdominal aorta. Rats were killed by exsanguination, and both kidneys and the liver were immediately isolated. The kidneys were cleaned and the liver freed from the attached vasculature before being weighed.

The protein content in the left kidney was determined in each rat in the day 0 group (normal rats), the Urea/14-day group, the Ringer/14-day group, and the DM/14-day group. The Lowry method [12] with bovine albumin as a standard was used to measure protein content.

Kidney function was assessed on the basis of the 24-h urine samples. Endogenous creatinine clearance and urea clearance were measured. Qualitative testing for urine sugar was performed using Testape (Eli Lilly and Co., Indianapolis, Ind., USA).

The blood glucose level was measured with the Dextrometer II (Ames, Miles Laboratories, Inc., Elkhart, Ind., USA) and Dextrostix (Ames, Miles-Sankyo Co., Ltd., Tokyo, Japan). All values were obtained with whole arterial blood samples collected during non-fasting periods (from 11.00 hours to 14.00 hours).

Serum blood urea nitrogen and creatinine as well as urine urea nitrogen and creatinine were determined using an autoanalyzer (Model 736; Hitachi, Ltd., Tokyo, Japan).

Plasma osmotic pressure was determined by the cryoscopic method with an automatic osmometer (Model OSA-21; Nikkiso Co., Ltd., Tokyo, Japan). 


\section{Statistical analysis}

Statistical analyses were performed using Student's $t$-test and paired Student's $t$-test. The difference was regarded as statistically significant if the $p$ value was not more than 0.05 . All data were expressed as the mean $\pm \mathrm{SD}$.

\section{Results}

\section{Body weight}

Body weights in the three experimental groups are shown in Table 1 . In control groups, with the exception of the 6-day group, the mean body weight values increased from baseline; weight increase was greater in rats treated for longer durations with Ringer solution. On the other hand, the Urea/2-day group and DM/2day group showed slight decreases in mean body weight from their respective baseline values (the decrease in each of these groups was within $4 \%$ of baseline). Since there were great differences among the groups in terms of body weight at the completion of the experiment, some of the data obtained were corrected for body weight (converted in terms of $100 \mathrm{~g}$ body weight).

\section{Blood glucose levels}

Blood glucose levels recorded in all interval groups are shown in Figure 1 A. All DM groups (from the 2-day to the 14-day groups) had significantly higher glucose levels than those of the day 0 group. No significant differences were observed between the Ringer and the urea groups. Neither the Ringer nor urea groups showed any significant changes compared with the day 0 group.

\section{Blood urea nitrogen}

The blood urea nitrogen values recorded in all interval groups are shown in Figure 1B. All urea groups had significantly higher values than those of the respective controls, and showed continuing azotaemia. None of the Ringer groups showed any significant changes compared with the day 0 group. The DM/6-day, DM/10-day and DM/14-day groups showed significantly higher values than that in the day 0 group, but the differences were small.

\section{Serum creatinine}

No serum creatinine values in any of the three treatment/four interval groups showed any changes compared with the day 0 group (Table 2).
Table 1. Body weight in the three treatment groups $(2,6,10$, 14 days)

\begin{tabular}{lrlll}
\hline Group & Day & $n$ & \multicolumn{2}{l}{\begin{tabular}{l} 
Body weight $(\mathrm{g})$ \\
\cline { 3 - 5 }
\end{tabular}} \\
& & & $\begin{array}{l}\text { Before } \\
\text { treatment } \\
(=\text { day } 0)\end{array}$ & $\begin{array}{l}\text { After } \\
\text { treatment }\end{array}$ \\
\hline Normal & 0 & 7 & $279.6 \pm 15.0$ & - \\
Ringer & 2 & 7 & $256.0 \pm 10.0$ & $267.0 \pm 12.6^{\mathrm{a}}$ \\
& 6 & 9 & $255.1 \pm 18.6$ & $265.7 \pm 32.5$ \\
& 10 & 9 & $254.0 \pm 14.9$ & $316.4 \pm 20.1^{\mathrm{a}}$ \\
& 14 & 8 & $260.0 \pm 10.4$ & $348.5 \pm 20.3^{\mathrm{a}}$ \\
Urea & 2 & 7 & $273.2 \pm 23.5$ & $262.7 \pm 25.3^{\mathrm{a}}$ \\
& 6 & 7 & $266.9 \pm 16.0$ & $260.4 \pm 16.7$ \\
& 10 & 7 & $251.0 \pm 11.1$ & $247.1 \pm 27.9$ \\
& 14 & 6 & $274.2 \pm 6.1$ & $297.3 \pm 18.9^{\mathrm{a}}$ \\
DM & 2 & 6 & $260.3 \pm 21.2$ & $251.0 \pm 18.3^{\mathrm{a}}$ \\
& 6 & 8 & $264.9 \pm 15.8$ & $256.6 \pm 24.1$ \\
& 10 & 6 & $253.3 \pm 11.1$ & $298.2 \pm 23.9^{\mathrm{a}}$ \\
& 14 & 9 & $274.2 \pm 15.2$ & $301.1 \pm 19.9^{\mathrm{a}}$ \\
\hline
\end{tabular}

Values are mean \pm SD.

a $p<0.05$ vs before each treatment

Table 2. Serum creatinine and plasma osmolality in the three treatment groups $(2,6,10,14$ days)

\begin{tabular}{lrlll}
\hline Group & Day & $n$ & $\begin{array}{l}\text { Serum } \\
\text { creatinine } \\
(\mu \mathrm{mol} / \mathrm{l})\end{array}$ & $\begin{array}{l}\text { Plasma } \\
\text { osmolality } \\
\text { (mosmol/kg) }\end{array}$ \\
\hline Normal & 0 & 7 & $45.1 \pm 3.5$ & $302.7 \pm 7.2$ \\
Ringer & 2 & 7 & $45.1 \pm 3.5$ & $296.9 \pm 5.0$ \\
& 6 & 9 & $46.0 \pm 6.2$ & $307.0 \pm 9.7$ \\
& 10 & 9 & $43.4 \pm 5.3$ & $302.6 \pm 5.9$ \\
& 14 & 8 & $47.8 \pm 4.4$ & $306.9 \pm 8.2$ \\
Urea & 2 & 7 & $41.6 \pm 7.1$ & $351.3 \pm 4.8^{\mathrm{a}}$ \\
& 6 & 7 & $50.4 \pm 9.7$ & $343.2 \pm 10.3^{\mathrm{a}}$ \\
& 10 & 7 & $41.6 \pm 9.7$ & $357.4 \pm 12.1^{\mathrm{a}}$ \\
& 14 & 6 & $39.8 \pm 15.9$ & $332.8 \pm 5.8^{\mathrm{a}}$ \\
DM & 2 & 6 & $50.4 \pm 7.1$ & $312.0 \pm 6.5^{\mathrm{b}}$ \\
& 6 & 8 & $48.7 \pm 7.1$ & $325.9 \pm 6.0^{\mathrm{b}}$ \\
& 10 & 6 & $46.0 \pm 3.5$ & $319.2 \pm 7.1^{\mathrm{b}}$ \\
& 14 & 9 & $49.6 \pm 4.4$ & $320.0 \pm 2.9^{\mathrm{b}}$ \\
\hline
\end{tabular}

Values are mean $\pm \mathrm{SD}$.

${ }^{a} p<0.05$ vs Ringer group of respective days;

${ }^{\mathrm{b}} p<0.05$ vs normal group (day 0 group)

\section{Urine flow}

The urine flow values in all urea, Ringer and DM groups are shown in Figure 1C. The urine flow values for the day 0 group were obtained from normal rats. There were no significant differences in urine flow rates between any of the Ringer groups and the day 0 group. In all urea groups, the urine volume began to show a marked increase immediately after the start of the experiment; significantly higher urine flow values than those of the controls (values in the Ringer groups) were maintained throughout the experimental period. Compared with the day 0 group, all DM groups 

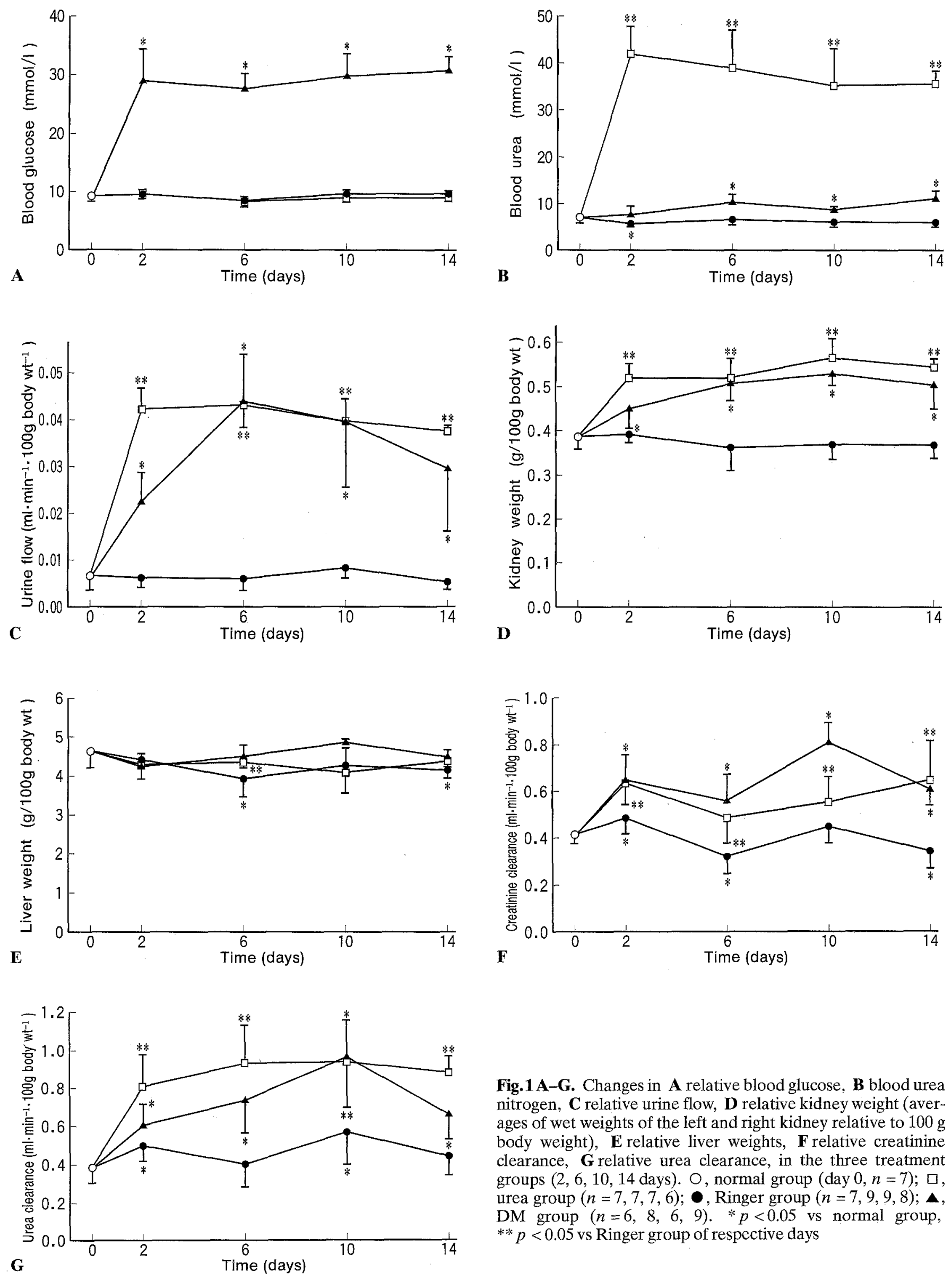

Fig. 1 A-G. Changes in A relative blood glucose, B blood urea nitrogen, $\mathbf{C}$ relative urine flow, $\mathbf{D}$ relative kidney weight (averages of wet weights of the left and right kidney relative to $100 \mathrm{~g}$ body weight), $\mathbf{E}$ relative liver weights, $\mathbf{F}$ relative creatinine clearance, $\mathbf{G}$ relative urea clearance, in the three treatment groups $(2,6,10,14$ days). $O$, normal group (day $0, n=7) ; \square$, urea group $(n=7,7,7,6)$; $\boldsymbol{\bullet}$, Ringer group $(n=7,9,9,8) ; \boldsymbol{\Lambda}$, DM group $(n=6,8,6,9)$. $* p<0.05$ vs normal group, ** $p<0.05$ vs Ringer group of respective days 
also showed significantly higher urine flow values, which were very similar to those observed in the urea groups.

\section{Kidney weight}

Changes in kidney weight are shown in Figure 1D. These values are relative kidney weights (averages of wet weights of the left and the right kidney relative to $100 \mathrm{~g}$ body weight). All the urea groups had markedly higher values than those found in their respective controls (Ringer groups) at the same time periods. The maximum increase in mean kidney weight in the urea group was $53 \%$ which was observed in the Urea/10-day group $(0.565 \pm 0.044 \mathrm{~g} / 100 \mathrm{~g}$ body weight) compared with the Ringer/10-day group $(0.369 \pm 0.034 \mathrm{~g} / 100 \mathrm{~g}$ body weight). All DM groups, from the 2-day $(0.449 \pm 0.043 \mathrm{~g} / 100 \mathrm{~g}$ body weight $)$ to the 14-day $(0.504 \pm 0.054 \mathrm{~g} / 100 \mathrm{~g}$ body weight) groups, had higher values than those in the day 0 group $(0.387 \pm$ $0.028 \mathrm{~g} / 100 \mathrm{~g}$ body weight). None of the Ringer-treated groups showed any significant changes compared with the day 0 group.

\section{Liver weight}

The wet weight of another parenchymatous organ, the liver was taken for each rat, and the values are shown in Figure $1 \mathrm{E}$. The mean weight in the Ringer/6-day group was significantly lower than that in the day 0 group, although the three remaining Ringer-treated groups had values similar to those in the day 0 group.

\section{Creatinine and urea clearance}

Changes in kidney function are shown in Figures $1 \mathrm{~F}$ and $\mathrm{G}$. Each group exhibited significant changes in the 24-h endogenous creatinine clearance value compared with the day 0 group. All the DM groups had values significantly higher than those in the day 0 group $(0.41 \pm$ $0.04 \mathrm{ml} \cdot \mathrm{min}^{-1} \cdot 100 \mathrm{~g}$ body weight $\left.{ }^{-1}\right)$. The value in the $\mathrm{DM} / 10$-day group $\left(0.81 \pm 0.09 \mathrm{ml} \cdot \mathrm{min}^{-1} \cdot 100 \mathrm{~g}\right.$ body weight $^{-1}$ ) was the highest among them. All the urea groups had values significantly higher than those of their respective controls, with the value in the 14-day group being the highest $\left(0.65 \pm 0.17 \mathrm{ml} \cdot \mathrm{min}^{-1} \cdot 100 \mathrm{~g}\right.$ body weight ${ }^{-1}$ ). Some of the values in the Ringertreated groups showed changes when compared to those in the day 0 group $\left(0.41 \pm 0.04 \mathrm{ml} \cdot \mathrm{min}^{-1} .100 \mathrm{~g}\right.$ body weight ${ }^{-1}$ ), but no definite trend was noted.

The urea clearance values obtained from the 24-h urine samples remained markedly higher in the urea groups than in the respective controls (Ringer-treated groups) throughout the experimental period (Fig. 1G). The 10-day group had the highest urea clearance value
Table 3. Renal total protein (left kidney) in the three treatment groups

\begin{tabular}{lll}
\hline Group & $n$ & $\begin{array}{l}\text { Renal total protein } \\
\text { (mg/100 g body weight) }\end{array}$ \\
\hline Normal & 7 & $63.5 \pm 5.4$ \\
Ringer/14 day & 8 & $62.6 \pm 4.9$ \\
Urea/14 day & 6 & $84.4 \pm 5.6^{\mathrm{a}}$ \\
DM/14 day & 9 & $75.6 \pm 5.4^{\mathrm{b}}$ \\
\hline
\end{tabular}

Values are mean $\pm \mathrm{SD}$.

${ }^{\mathrm{a}} p<0.05$ vs Ringer $/ 14$ day group;

${ }^{\mathrm{b}} p<0.05$ vs normal group (day 0 group)

$\left(0.94 \pm 0.24 \mathrm{ml} \cdot \mathrm{min}^{-1} \cdot 100 \mathrm{~g}\right.$ body weight $\left.{ }^{-1}\right)$. All the DM groups (from the 2-day to the 14-day groups) showed significantly higher values than those in the day 0 group. The 10-day group had the highest value $\left(0.96 \pm 0.19 \mathrm{ml} \cdot \mathrm{min}^{-1} \cdot 100 \mathrm{~g} \mathrm{body}\right.$ weight $\left.{ }^{-1}\right)$. Some of the values in the Ringer-treated groups demonstrated changes when compared to those in the day 0 group $\left(0.39 \pm 0.08 \mathrm{ml} \cdot \min ^{-1} \cdot 100 \mathrm{~g}\right.$ body weight $\left.{ }^{-1}\right)$, but no definite trend was seen.

\section{Renal protein}

Data on the protein content in the left kidney obtained from the day 0 group (normal rat group) and from the 14-day groups for each of the three treatments are shown in Table 3. The value in the Ringer/14-day group was not significantly different from that in the day 0 group, while the value in the Urea/14-day group was significantly higher than that in the Ringer group. The value in the DM/14-day group was significantly higher than that in the day 0 group.

\section{Plasma osmolality}

Changes in the osmotic pressure of plasma separated from arterial blood are shown in Table 2. All the urea groups (from the 2-day to the 14-day groups) had values significantly higher than those in the respective controls. All the DM groups also had values significantly higher than those in the day 0 group, but the values in the urea groups were higher than those in the DM group. No values in any of the Ringer groups showed any significant changes compared with the day 0 group.

\section{Discussion}

To study the effects of continuous osmotic diuresis which were not associated with hyperglycaemia on the rat kidney, we infused male Wistar rats with a hypertonic urea solution. Brown et al. [13] suggested that the effects of osmotic diuresis observed in diabetic nephropathy should be studied in isolation from hypergly- 
caemia, using a simple model that excludes other variables. For example, mannitol injections have been used to experimentally induce osmotic diuresis in normal rats [14]. However, osmotic diuresis associated with hyperglycaemia has been shown to be markedly different from osmotic diuresis induced by mannitol or a hypertonic sodium chloride solution [15-17]. The increase in plasma osmotic pressure due to hyperglycaemia is unlikely to cause an effective osmotic stimulus at osmoreceptors. Thus, the osmotic diuresis associated with hyperglycaemia does not stimulate vasopressin secretion as does the osmotic diuresis induced by mannitol [15-17]. Urea is an endogenous, slightly toxic substance which is also a final metabolite in ureaexcreting animals such as mammals. When used to induce osmotic diuresis, urea does not cause vasopressin secretion, leading several researchers to suggest that urea-induced osmotic diuresis is similar to the osmotic diuresis caused by glucose in the diabetic state [15-17]. Because of this similarity, urea was used to induce osmotic diuresis in this study.

All previous studies using urea to induce osmotic pressure $[18,19]$ addressed the effects of acute osmotic diuresis; to the best of our knowledge, this is the first investigation on the effects of continuous urea-induced osmotic diuresis.

It has also been pointed out that different kinds of protein, even when administered in similar amounts, cause different degrees of renal hypertrophy and glomerular hyperfiltration. The cause for these differences has not been explained [20,21]. It has also been reported that different kinds of protein cause similar increases in the excretion of urea [22]. These studies suggest that nitrogen loading or increased excretion of urea itself is an unlikely cause of renal hypertrophy or glomerular hyperfiltration. Therefore, the effects of exogenous urea observed in this experiment may not have been due to nitrogen loading or increased urea excretion, but the result of osmotic diuresis.

The urea groups also showed a marked increase in plasma osmotic pressure. Thus, we think it reasonable to conclude that osmotic diuresis and a hyperosmotic state can result from urea administration. These two phenomena are difficult to evaluate independently because they are seemingly inseparable.

In this experiment, continuous administration of a large dose of urea $\left(30.03 \mathrm{~g} \cdot \mathrm{kg}\right.$ body weight ${ }^{-1}$. day $\left.{ }^{-1}\right)$ induced osmotic diuresis and produced a urine flow rate (about $0.04 \mathrm{ml} \cdot \mathrm{min}^{-1} .100 \mathrm{~g}$ body weight ${ }^{-1}$ ) comparable to that observed in rats with diabetes (induced by $55 \mathrm{mg} / \mathrm{kg}$ of streptozotocin, i.v.).

Forced continuous osmotic diuresis induced by urea caused a marked increase in kidney weight and glomerular hyperfiltration as early as experiment day 2 . These increased levels were maintained throughout the 14-day experimental period. This pattern was very similar to the pattern of renal hypertrophy and glomerular hyperfiltration observed in the DM groups.
Hyperfiltration in clinical diabetes has been attributed partly to acute and rapidly reversible haemodynamic changes and partly to renal hypertrophy. Our study considered only the mechanisms responsible for renal hypertrophy.

The relative liver weight (relative to $100 \mathrm{~g}$ body weight) remained almost constant during the experimental period in all three treatment groups, indicating that dehydration was not a factor in body weight changes. Thus, the increase in relative kidney weight (relative to $100 \mathrm{~g}$ body weight) observed in the study cannot be attributed to dehydration.

Because of the simultaneous increase in the protein content in the kidney, the increase in the relative kidney weight may not have been due to fluid accumulation, but to renal hypertrophy/hyperplasia. These results suggest that osmotic diuresis may play a major independent role in the pathogenesis of renal hypertrophy and glomerular hyperfiltration observed early in the development of diabetes.

This experiment does not explain the mechanism by which osmotic diuresis causes renal hypertrophy and glomerular hyperfiltration. Nor does it determine which of these two phenomena appeared first, because administration of urea resulted in the simultaneous occurrence of both. Furthermore, our study does not rule out the possibility of other factors besides osmotic diuresis as a causative factor of these phenomena. However, the study does suggest that a single factor, osmotic diuresis, may induce these two phenomena. The effects of osmotic diuresis on the kidney are worthy of further investigation.

Acknowledgements. We thank Dr. H.Fujiwara and Mr. M. Aoi for technical assistance.

\section{References}

1. Stalder G, Schmid R (1959) Severe functional disorders of glomerular capillaries and renal hemodynamics in treated diabetes mellitus during childhood. Ann Pediatr 193:129-138

2. Mogensen CE, Andersen MJF (1973) Increased kidney size and glomerular filtration rate in early juvenile diabetes. Diabetes 22: 706-712

3. Christiansen JS, Gammelgaard J, Frandsen M, Parving HH (1981) Increased kidney size, glomerular filtration rate and renal plasma flow in short-term insulin-dependent diabetics. Diabetologia 20: 451-456

4. Mogensen CE, Christensen CK, Vittinghus E (1983) The stages in diabetic renal disease. With emphasis on the stage of incipient diabetic nephropathy. Diabetes 32 [Suppl 2]: 64-78

5. Seyer-Hansen K (1976) Renal hypertrophy in streptozotocin-diabetic rats. Clin Sci Mol Med 51: 551-555

6. Brenner BM, Hostetter TH, Olson JL, Rennke HG, Venkatachalam MA (1981) The role of glomerular hyperfiltration in the initiation and progression of diabetic nephropathy. Acta Endocrinol 97 [Suppl 242]: 7-10

7. Østerby R, Gundersen HJG (1981) Fast accumulation of basement membrane material and the rate of morphological changes in acute experimental diabetic glomerular hypertrophy. Diabetologia 18: 493-500 
8. Seyer-Hansen K, Hansen J, Gundersen HJG (1980) Renal hypertrophy in experimental diabetes. A morphometric study. Diabetologia 18:501-505

9. Wiseman M, Viberti GC (1983) Kidney size and glomerular filtration rate in type 1 (insulin-dependent) diabetes mellitus revisited. Diabetologia 25:530

10. Hostetter TH, Brenner BM (1982) The case for intrarenal hypertension in the initiation and progression of diabetic and other glomerulopathies. Am J Med 72: 375-380

11. Steiger E, Vars HM, Dudrick SJ (1972) A technique for longterm intravenous feeding in unrestrained rats. Arch Surg 104: 330-332

12. Lowry OH, Rosebrough NJ, Farr AL, Randell RJ (1951) Protein measurement with the Folin phenol reagent. J Biol Chem 193: 265-271

13. Brown DM, Andres GA, Hostetter TH, Mauer SM, Price R, Venkatachalam MA (1982) Kidney complications. Diabetes 31 [Suppl 1]: 71-81

14. Seely JF, Dirks JH (1969) Micropuncture study of hypertonic mannitol diuresis in the proximal and distal tubule of the dog kidney. J Clin Invest 48:2330-2340

15. Sladek CD, Knigge KM (1977) Osmotic control of vasopressin release by rat hypothalamo-neurohypophyseal explants in organ culture. Endocrinology 101: 1834-1838
16. Ishikawa S, Saito T, Yoshida S (1980) The effect of osmotic pressure and angiotensin II on arginine vasopressin release from guinea pig hypothalamo-neurohypophyseal complex in organ culture. Endocrinology 106: 1571-1578

17. Zerbe RL, Robertson GL (1983) Osmoregulation of thirst and vasopressin secretion in human subjects: effect of various solutes. Am J Physiol 244: E607-E614

18. Kauker ML, Lassiter WE, Gottschalk CW (1970) Micropuncture study of effects of urea infusion on tubular reabsorption in the rat. Am J Physiol 219: 45-50

19. Edwards BR, Novakova A, Sutton RAL, Dirks JH (1973) Effect of acute urea infusion on proximal tubular reabsorption in the dog kidney. Am J Physiol 224: 73-79

20. Halliburton IW (1968) The effect of unilateral nephrectomy and of diet on the composition of the kidney. In: Nowinski WW, Goss RJ (eds) Compensatory renal hypertrophy. Academic Press, New York, pp 101-128

21. Jones G, Lee K, Swaminathan R (1985) Glomerular filtration response to acute protein load. Lancet 12:838

22. Dhaene M, Sabot JP, Philippart Y, Doutrelepont JM, Vanherweghem JL (1987) Effect of acute protein loads of different sources on glomerular filtration rate. Kidney Int 32 [Suppl 22]: S-25-S-28 